\title{
PERANCANGAN RUANG KERJA DOSEN DAN PENATAAN DOKUMEN MENGGUNAKAN METODE 5S DI JURUSAN TEKNIK INDUSTRI, UNIVERSITAS TRISAKTI
}

\author{
Arnes Faradilla*), Winnie Septiani, Nora Azmi, Syafa Kansa \\ Laboratorium Desain Sistem Kerja dan Ergonomi \\ Jurusan Teknik Industri, Fakultas Teknologi Industri, Universitas Trisakti
}

(Received: September 2, 2018/ Accepted: July 9, 2019)

\begin{abstract}
Abstrak
Setiap Dosen memiliki tugas utama terkait dengan tridharma yaitu Pendidikan dan Pengajaran, Penelitian, Pengabdian Kepada Masyarakat (PKM), dan Penunjang Tridharma. Dokumen yang digunakan banyak dan harus disimpan dengan rapi di ruang kerja untuk keperluan kegiatan Dosen seperti Beban Kerja Dosen (BKD) dan kepangkatan. Hasil penelitian pendahuluan menunjukkan sebanyak $62,5 \%$ Dosen menyatakan kesulitan dalam menyimpan dokumen di ruang kerja dan sebanyak 81,25\% menyatakan perlu adanya perbaikan di ruang kerja. Penelitian ini bertujuan untuk merancang ruang kerja Dosen dan penataan dokumen menggunakan metode 5S. Penelitian diawali dengan penguraian aktivitas Dosen dan pengelompokkan dokumen, perancangan ruang kerja dan fasilitas penyimpanan dokumen, identifikasi kondisi awal ruang kerja, penerapan $5 S$ dan evaluasi hasil rancangan menggunakan Office $5 S$ Audit Checklist. Penelitian ini menghasilkan penataan dokumen yang tersusun rapi berdasarkan prinsip 5 S, rancangan almari dengan kriteria biaya yang tidak terlalu mahal, ukuran dan desain disesuaikan dengan ukuran ruangan dan dokumen yang akan disimpan. Hasil penilaian performansi $5 S$ di ruang kerja Dosen sebelum penerapan $5 S$ diperoleh skor rata-rata sebesar 56,83 dengan kategori rating fair, dan setelah penerapan $5 S$ skor rata-rata menjadi 92 dengan kategori rating excellent yang menunjukan peningkatan sebesar 50\%.
\end{abstract}

Kata Kunci: ergonomi; office ergonomi; office $5 S$ audit checklist; score $5 S$

\begin{abstract}
[Planning Lecturer Working Room and Document Arrangement Using 5S Method In Department Industrial Engineering, Trisakti University] Every lecturer has main duty to fulfill Tridharma Perguruan Tinggi which are Education and Teaching, Research and PKM. All of the documents must be stored in order to easier the lecturer to necessity of BKD and raising the grade. The preliminary research about the lecture's working room, the result stated that as much as $62.5 \%$ lectures have difficulties to store the documents in their working room. Several lecturers stated that the facilities such as board is unappropriate. Another $81.25 \%$ of lecturers stated is necessary to improve the system to store the documents their working room. The purpose of this research is to design the lecture's working room and organize the documents using $5 S$ method. The research is began with describing of lecturer activities and documents grouping, designing of lecturer's room and facility of documents storage, initial identification of lecturer's room, application of $5 S$ method and evaluation of this application. This reseach has result of document structuring based on $5 S$ method, document board which have criterion such as cheaper price, size and design appropriate with the room and documents will be stored. The result of $5 S$ performance in lecturer's room before using $5 S$ method id 56.83 which is fair category, and after using $5 S$ the score is increase become 92 which is excellent catogory. It can be conclude that there is increasing the score almost $50 \%$.
\end{abstract}

Keywords: ergonomic; office ergonomic; office $5 S$ audit checklist; score $5 S$

\footnotetext{
*)Penulis Korespondensi.

E-mail: arnes.faradilla@trisakti.ac.id
}

\section{Pendahuluan}

Ruang kerja Dosen merupakan tempat Dosen dalam melaksanakan kegiatan dan tugas. Setiap Dosen difasilitasi berupa ruang kerja beserta fasilitas 
penyimpanan dokumen dalam menunjang kegiatan Dosen. Kegiatan Dosen terkait tridharma antara lain Pendidikan dan Pengajaran, Penelitian, PKM atau Pengabdian Kepada Masyarakat, dan Penunjang Tridharma. Kegiatan tersebut menggunakan banyak dokumen, sehingga harus ditata agar dokumen tersebut tersimpan dengan baik dan tersedia saat dibutuhkan.

Penelitian pendahuluan terkait ruang kerja Dosen Teknik Industri, Universitas Trisakti dilakukan dengan menggunakan kuesioner terbuka sebanyak 16 Dosen dengan 6 Dosen Senior, 4 Dosen Menengah dan 6 Dosen Muda menggunakan teknik stratified sampling yaitu pengambilan berdasarkan tingkatan (strata) atau kelompok pada populasi. Hasil yang diperoleh yaitu $62,5 \%$ menyatakan mengalami kesulitan dalam penyimpanan dokumen di ruang kerja. Ruang kerja Dosen berukuran 3,08 x $3 \mathrm{~m}$ dengan fasilitas ruangan berupa kursi, meja dan almari. Beberapa Dosen menyatakan keluhan fasilitas di ruang kerja, antara lain almari yang kurang sesuai dengan kebutuhan, ruang simpan dokumen yang kurang luas, almari yang besar tetapi tidak fungsional dan terlalu banyak file maupun dokumen-dokumen lainnya, dan fasilitas ruang kerja yang banyak debu. Hasil lainnya yaitu $81,25 \%$ responden menyatakan perlu adanya perbaikan ruang kerja, antara lain perbaikan sistem peletakkan penyimpanan dokumen yang mudah dalam pengambilannya, penyusunan dokumen dan peralatan yang terstruktur rapi sehingga mudah dalam mencari dokumen, peruntukkan spacespace atau ruangan yang sesuai keperluan. Hasil penelitian pendahuluan tersebut menjadi dasar diperlukannya penelitian perbaikan untuk merancang ruang kerja dan penataan dokumen Dosen dengan menggunakan metode $5 \mathrm{~S}$.

Beberapa penelitian telah dilakukan oleh beberapa peneliti terkait 5S. Agustin dan Purnomo (2013) melakukan implementasi 5S pada divisi packaging di CV. Valasindo dengan melibatkan pekerja untuk memperlancar penerapan 5S. Penelitian ini menggunakan wawancara dan kuesioner untuk melihat dampak perubahan 5S. Hasil yang diperoleh yaitu kondisi penataan barang terlihat rapi, meminimalkan gerakan waste, dan peningkatan jumlah packaging sebesar 12.5\%. Gupta dan Jain (2015) melakukan implementasi 5S untuk mengatur peralatan di Shop Floor Ambala yang menghasilkan waktu pencarian peralatan berkurang, menghemat biaya pengeluaran pabrik, serta lingkungan kerja menjadi teratur dan tertata rapi. Gurel (2013) melakukan penerapan $5 \mathrm{~S}$ dalam manajemen hotel yang menghasilkan bahwa $5 \mathrm{~S}$ menjadi metode yang memenuhi persyaratan dalam manajemen kualitas pada hotel. Ramesh et al (2014) mengaplikasikan 5S di area kerja Biomass Processing Unit dan melakukan rating $5 \mathrm{~S}$. Hasil yang didapatkan yaitu perubahan nyata pada lantai produksi dengan meningkatnya semangat kerja dan produktivitas. Sari et al (2017) menerapkan 5S untuk melakukan perbaikan secara kontinu dalam penataan barangbarang laboratorium DSK\&E. Tools yang digunakan pada penelitian ini menggunakan $5 S$ Chekclist dengan hasil peningkatan performansi 5S sebanyak $50 \%$ dan penggunaan area laboratorium yang lebih baik, menghemat waktu pencarian peralatan dan meningkatkan budaya dan semangat $5 \mathrm{~S}$ pada pekerja. Soesilo (2017) melakukan implementasi 5S di area chrome platting PT. NKG Busi. Penelitian tersebut membuat rak untuk mengganti tatakan box untuk mengeringkan produk. Hasil yang diperoleh yaitu area produksi menjadi longgar, pembuatan rak menghilangkan pemborosan box, dan meningkatkan produktivitas. Widianti et al (2015) menerapkan 5S di lingkungan kerja penelitian XYZ karena ketidakteraturan lingkungan kerja dengan adanya waste. Penerapan 5S membantu penataan lingkungan kerja kelompok penelitian menjadi aman, nyaman, bersih, dan sehat.

Penelitian ini bertujuan untuk merancang ruang kerja dan penataan dokumen di salah satu ruang kerja Dosen Teknik Industri, Universitas Trisakti yang menjadi obyek penelitian dengan melakukan penerapan metode 5S. Metode lain yang juga diterapkan dalam penelitian ini antara lain perancangan dan pengembangan produk dan antropometri dalam perancangan fasilitas penyimpanan dokumen, dan display ergonomi dalam membuat display pengingat 5S. Penelitian ini diharapkan dapat memberikan kemudahan untuk Dosen dalam menata dan menyimpan dokumen, serta membawa dampak kebiasaan individu yang baik dalam menerapkan budaya kerja $5 \mathrm{~S}$ di ruang kerja Dosen.

\section{Metode Penelitian}

Jumlah responden yang digunakan pada penelitian ini berjumlah 27 orang dengan pembagian responden penelitian pendahuluan sebanyak 15 orang, pembuatan almari sebanyak 6 orang dan evaluasi akhir $5 \mathrm{~S}$ sebanyak 6 orang. Metode yang digunakan dalam pemilihan sampel adalah stratified sampling. Penguraian tugas Dosen dilakukan disesuaikan dengan SISTER DIKTI.

Metodologi yang digunakan pada penelitian ini menggunakan metode perancangan produk menggunakan Quality Function Deployment (QFD) (Ulrich dan Eppinger, 2001) dan metode 5S. Perancangan produk digunakan untuk merancang almari yang disesuaikan dengan kebutuhan dokumen. Berikut merupakan tahapan dalam metode Office Audit 5S:

\subsection{Pengelompokkan Kebutuhan Dokumen Dosen}

Tugas Dosen berdasarkan Tridharma dikelompokkan menjadi tiga kelompok yaitu Pendidikan dan Pengajaran, Penelitian, PKM dan kegiatan penunjang lainnya. Dokumen-dokumen yang dibutuhkan telah disusun berdasarkan SISTER DIKTI (Sistem Informasi Sumberdaya Terintegrasi) yang dikembangkan oleh Kementerian 
RISTEKDIKTI Republik Indonesia untuk pendokumentasian aktivitas dosen dan membangun portofolio yang mengkompilasikan seluruh aktivitas tridharma, sehingga setiap Dosen memiliki kebutuhan dokumen yang sama. Berikut merupakan penjabaran terkait dengan dokumen kebutuhan Dosen:

\section{a. Pendidikan dan Pengajaran}

1. Melakukan kegiatan pengajaran

2. Membina Bimbingan Perwalian Mahasiswa

3. Bimbingan Tugas Akhir dan Kerja Praktik

4. Pengujian Tugas Akhir dan Kerja Praktik

5. Mengembangkan Bahan Ajar

6. Menjadi Pembimbing untuk Dosen Muda

\section{b. Penelitian}

1. Menghasilkan Karya Penelitian

2. Menyadur Literatur untuk Karya Ilmiah

3. Menghadiri Seminar Karya Ilmiah

4. Melakukan Publikasi

5. Paten Karya Ilmiah

\section{c. PKM}

1. Melakukan Kegiatan PKM

2. Menjadi Pembicara PKM

d. Penunjang Lainnya

1. Kepanitiaan Pada Lomba Mahasiswa

2. Menjadi Anggota Profesi

3. Menjadi Pengelola Jurnal

4. Mendapat Penghargaan

\subsection{Merancang Fasilitas Penyimpanan Dokumen}

Urutan proses perancangan dan pengembangan produk diacu dari buku Perancangan dan Pengembangan Produk menurut Ulrich dan Eppinger (2001). Penggambarkan klasifikasi alternatif konsep menggunakan pohon klasifikasi dari segi desain bentuk almari penyimpanan berupa laci atau rak, material bahan baku berupa layered atau pertikel board, dan material pewarnaan berupa cat atau full dekosit HPL.

Penentuan alternatif tersebut berdasarkan hasil kesimpulan pembahasan wawancara dan hasil survey dalam pemilihan material yang di mana alternatif tersebut dibutuhkan pemilihan lebih lanjut. Terdapat 8 alternatif konsep dan yang terpilih adalah konsep D yaitu desain almari berbentuk rak, bahan baku almari dibuat dari bahan layered dan material pewarnaan menggunakan full dekosit HPL.

Penentuan dimensi ukuran almari kayu disesuaikan berdasarkan dimensi antropometri orang Indonesia. Ruang kerja Dosen yang dilakukan penataan memiliki luas ruangan $3,08 \mathrm{~m} \times 3 \mathrm{~m}$.

\subsection{Penataan Ruang Kerja}

Penataan ruang kerja dilakukan dengan menggunakan metode 5S. Menurut Osada (2016), akivitas $5 \mathrm{~S}$ dikantor harus dipusatkan pertama pada fungsi utama ruang kantor, di mana sejumlah orang menghasilkan pekerjaan berupa administrasi dan informasi. Terdapat 5 tahapan dalam metode $5 \mathrm{~S}$ yang diterapkan pada ruang kerja Dosen:

\section{Seiri/ Pemilahan}

Menurut Suwondo (2012) antara lain Seiri atau meringkas yaitu menyingkirkan atau membuang barang - barang yang tidak dapat digunakan kembali dengan barang yang dibutuhkan untuk aktivitas kerja. Penyortiran barang untuk membuang dokumen yang tidak dibutuhkan dan menyimpan dokumen yang masih digunakan. Gambar 1 menunjukkan hasil pemilahan dokumen yang dilakukan.

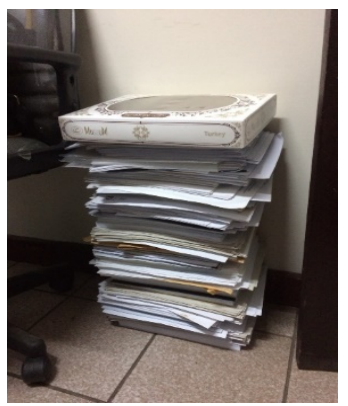

Gambar 1. Hasil Pemilahan Dokumen

\section{Seiton/ Penataan}

Penataan dokumen di ruang kerjaa yang disesuaikan dengan kegiatan Dosen. Proses penentuan pengelompokkan dokumen dilakukan proses verifikasi agar pengelompokkan sesuai dengan kebutuhan user. Verifikasi dilakukan dengan tiga tahap, yaitu tahap pertama yaitu berdasarkan perkiraan dari hasil kuesioner terbuka. Tahapan kedua verifikasi dilakukan oleh user atau Dosen berdasarkan perkiraan kebutuhan. Tahapan verifikasi terakhir yaitu sesuai dengan kondisi nyata ruang kerja Dosen (user). Tabel 1 merupakan kode dan warna pengelompokkan dokumen.

Tabel 1. Kode dan Warna Pengelompokkan Dokumen

\begin{tabular}{cll}
\hline Kode & \multicolumn{1}{c}{ Kegiatan/ Dokumen } & \multicolumn{1}{c}{ Warna } \\
\hline A & Bidang Penelitian dan & Kuning \\
B & $\begin{array}{l}\text { Pengajaran } \\
\text { Bidang Penelitian }\end{array}$ & Biru \\
C & $\begin{array}{l}\text { Bidang Pengabdian } \\
\text { Kepada Masyarakat }\end{array}$ & Pink \\
& Bidang Penunjang & Hijau \\
D & Perguruan Tinggi & Orange \\
E & Lainnya & \\
\hline
\end{tabular}

Penggunaan kode huruf dan warna sebagai alat untuk mengdentifikasi kelompok dokumen yang dibuat dalam bentuk label. Label dibuat yang memberikan informasi berupa warna label dan kode huruf sesuai kelompok kegiatan, nama dokumen, dan nama Dosen serta NIDN yang menunjukan kepemilikan dokumen.

Huruf dan label yang digunakan untuk membantu Dosen ketika meletakkan dokumen dan mencari dokumen. Hasil dari aspek penerapan Seiton dapat dilihat pada Gambar 2. 


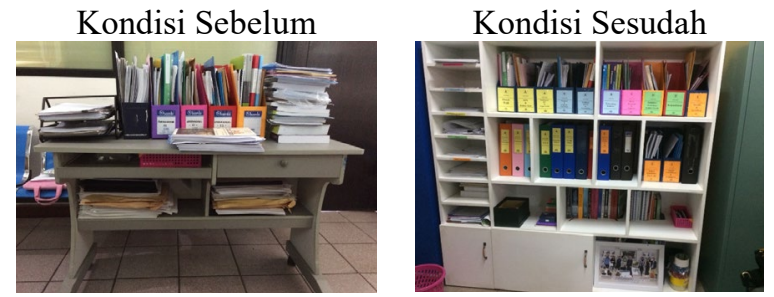

Gambar 2. Hasil Penerapan Seiton/ Penataan

\section{Seiso/ Pembersihan}

Proses pembersihan di ruang kerja Dosen membersihkan fasilitas, peralatan, dan dokumen Dosen dari sampah, debu dan kotoran. Proses pembersihan harian juga dapat dikoordinasi oleh petugas kebersihan atau Karfati (Karyawan Fakultas Teknologi Industri) di ruang kerja agar ruang kerja tetap bersih terjaga. Gambar 3 menunjukkan hasil pembersihan ruang kerja yang telah tertata rapi.

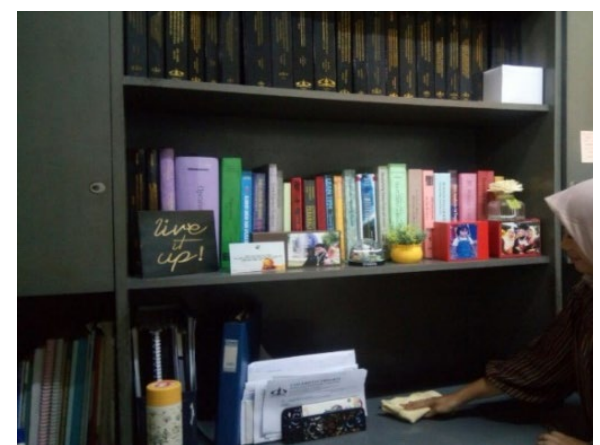

Gambar 3. Hasil Pembersihan Ruang Kerja

\section{Seiketsu/ Penetapan Standar}

Tahapan Seiketsu atau penetapan standar untuk merawat atau menjaga kondisi $3 \mathrm{~S}$ sebelumnya. Salah satu tahapan aspek ini yaitu membuat display pengingat 5S. Gambar 4 menunjukkan hasil display yang dibuat sebagai pengingat $5 \mathrm{~S}$ diruang kerja.

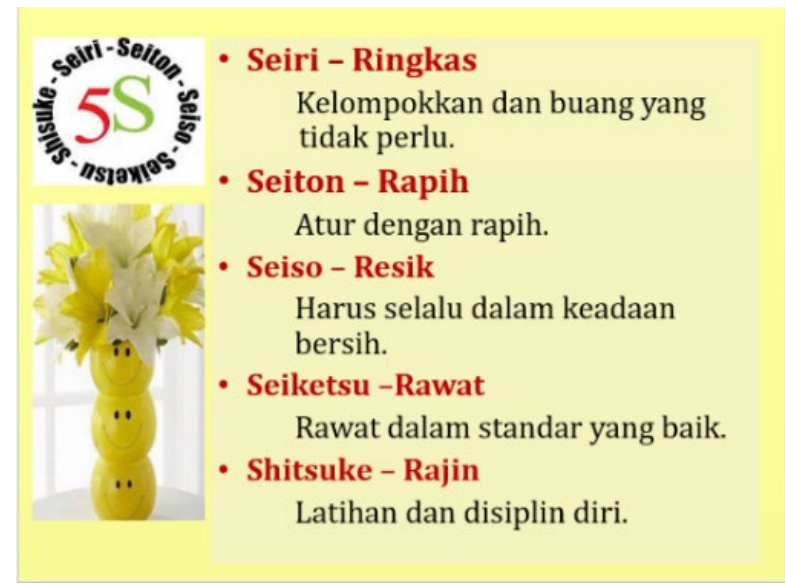

Gambar 4. Display Pengingat 5S

Display yang digunakan untuk pengingat $5 \mathrm{~S}$ di ruang kerja Dosen dirancang dengan tampilan yang tidak membosankan, mudah diingat, dan ringkas. Display juga dibuat sesuai dengan kebutuhan user akan tampilan yang menarik di ruang kerjanya.
Penempatan display 5S di ruang kerja Dosen dapat dilihat pada Gambar 5.

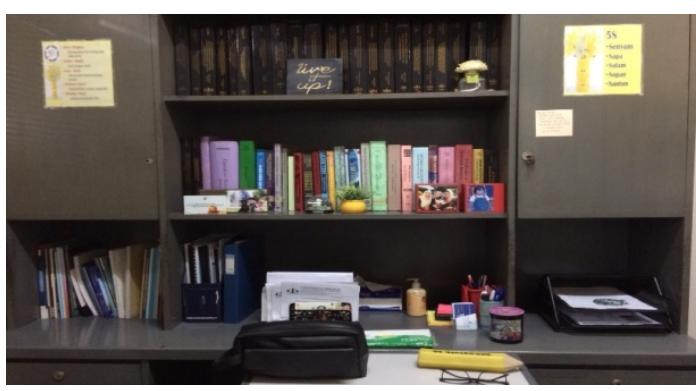

Gambar 5. Peletakkan display 5S

Penempatan display tersebut juga menandakan bahwa ruang kerja Dosen tersebut mengikuti budaya kerja 5S dan penempatan display diletakan sebagai pengingat untuk mempertahankan kondisi $5 \mathrm{~S}$ di ruang kerja.

\section{Shitsuke/ Pembiasaan}

Tahapan terakhir merupakan tahapan Shitsuke atau pembiasaan kondisi $5 \mathrm{~S}$ di ruang kerja. Tahapan ini merupakan tahapan yang paling sulit, karena harus mempertahankan dan tanggung jawab untuk menjaga kondisi 5S. Tahapan ini juga dapat dilakukan dengan melakukan evaluasi penilaian kondisi ruang kerja tiap bulannya untuk mengetahui kondisi dan sebagai acuan untuk meningkatkan $5 \mathrm{~S}$ di ruang kerja.

\section{Hasil dan Pembahasan}

Hasil yang diperoleh dari pengembangan produk adalah almari dokumen yang disesuaikan dengan luas ruangan dan kebutuhan dokumen. Gambar 6 merupakan hasil dari almari yang telah didesain.

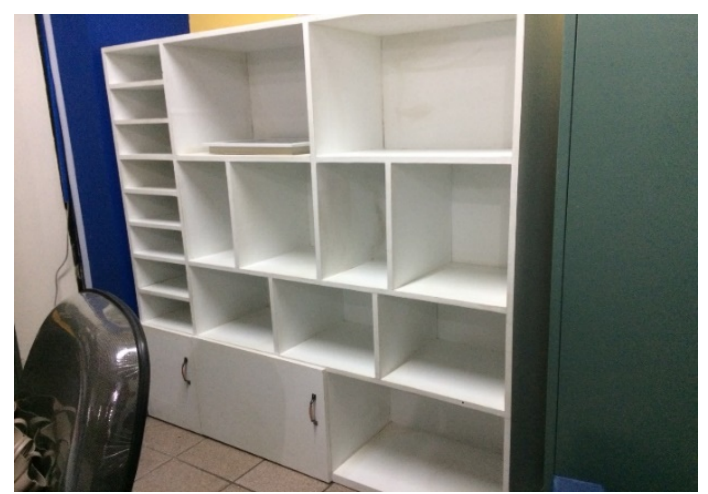

Gambar 6. Hasil Desain Almari Dokumen

Dimensi yang digunakan adalah tinggi tubuh posisi berdiri tegak dengan persentil $50 \%$ yang bertujuan untuk menentukan tinggi almari dokumen yang dapat digunakan oleh pengguna yang berada pada persentil 50\% sebesar $152,06 \mathrm{~cm}$. Ukuran tinggi almari dokumen yang dibuat menjadi $160 \mathrm{~cm}$ dengan toleransi tambahan ukuran sekitar 7,94 cm dikarenakan dalam pembuatan almari untuk - 


\section{IDENTIFIKASI AWAL PERFORMANSI 5S RUANG KERJA DOSEN}

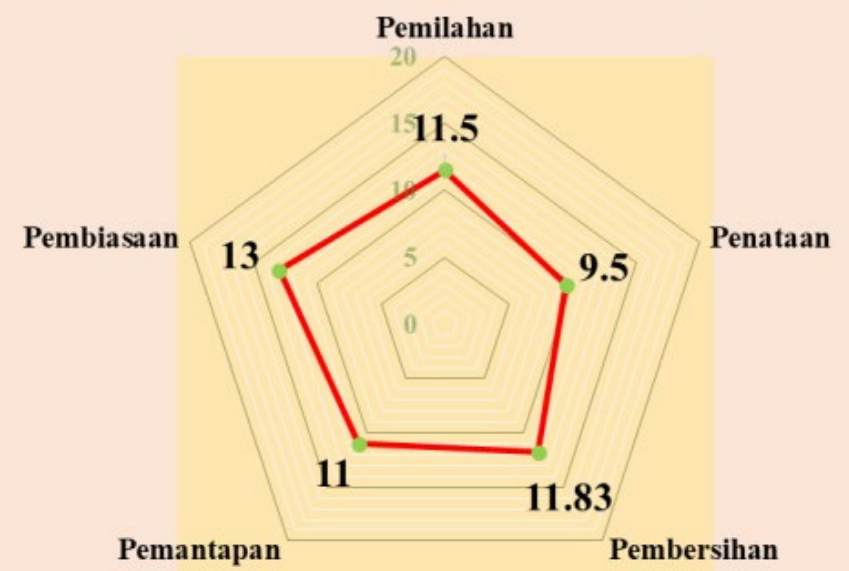

Gambar 7. Radar Chart Sebelum Penerapan 5S

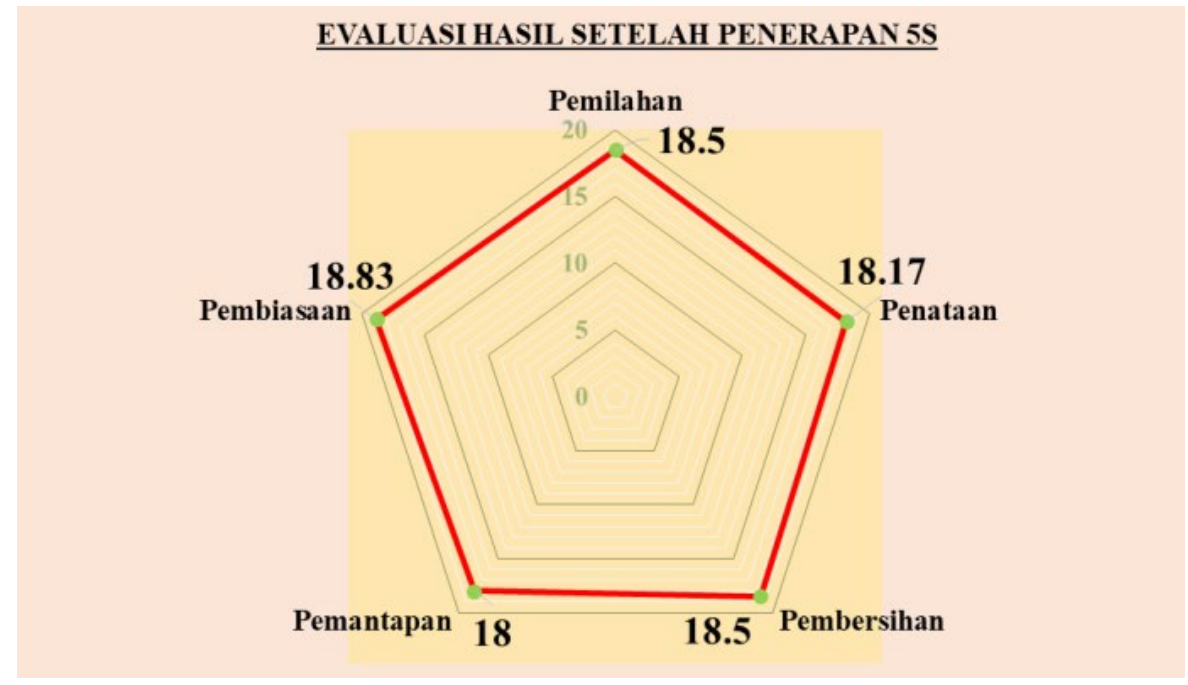

Gambar 8. Radar Chart Setelah Penerapan 5S

menyesuaikan dengan ketebalan bahan baku kayu. Dimensi panjang sebesar $160 \mathrm{~cm}$ dan lebar almari sebesar $40 \mathrm{~cm}$ ditentukan dari ukuran panjang sarana penyimpanan dokumen seperti boxfile, odner, dan handbook yang sesuai dengan kebutuhan untuk menyimpan dokumen dan disesuaikan berdasarkan ukuran ruang obyek penelitian.

Setelah dilakukan penerapan metode $5 \mathrm{~S}$ di ruang kerja Dosen, kemudian dilakukan evaluasi penerapan menggunakan Office Audit 5S Checklist. Evaluasi dilakukan untuk melihat perbedaan yang terjadi sebelum dan setelah dilakukan penerapan $5 \mathrm{~S}$ diruang kerja Dosen, kemudian dilakukan analisis terhadap peningkatan atau penurunan dari penerapan tersebut.

Parameter yang diperhatikan dalam Office Audit $5 S$ checklist adalah dari aspek pemilihan, penataan, pembersihan, pemantapan dan pembiasaan. Gambar 7. menunjukkan radar chart dari sebelum dilakukan penerapan 5S diruang kerja Dosen.

Radar chart identifikasi awal menunjukan gambaran penyimpangan dari hasil rata-rata tiap aspek dengan penyimpangan terkecil yaitu aspek pembiasaan dengan skor tertinggi sebesar 13 dan penyimpangan terbesar yaitu aspek penataan dengan skor terkecil yaitu sebesar 9.5 yang berarti aspek penataan di ruang kerja merupakan aspek yang terburuk. Radar chart setelah perbaikan dapat dilihat pada Gambar 8.

Skor 5S hasil evaluasi pada radar chart terlihat cenderung menjauhi titik tengah yang berarti semakin kecil penyimpangan dari tiap aspek $5 \mathrm{~S}$ di ruang kerja. Aspek pembiasaan tetap menjadi aspek dengan skor terbesar, yaitu 18,83 yang berarti Dosen mematuhi aturan dan mempertahankan kondisi $5 \mathrm{~S}$ di ruang kerja dengan baik. Aspek penataan sebelumnya merupakan aspek terburuk sengan skor 5, mengalami peningkatan menjadi sebesar 18,7 yang berarti kondisi penataan dokumen dan barang menjadi lebih baik dari sebelumnya. Hasil tersebut menunjukkan bahwa kondisi ruang kerja Dosen mengalami peningkatan yang signifikan, peningkatan rating dari fair menjadi excellent, dan penurunan penyimpangan tiap aspek $5 \mathrm{~S}$ pada kondisi ruang kerja saat ini. 


\section{Kesimpulan}

Penerapan metode 5S dapat diterapkan tidak hanya di bagian produksi tetapi juga dapat diterapkan di bagian ruang kerja. Metode $5 \mathrm{~S}$ dapat membantu Dosen dalam menata dan mendokumentasikan segala file-file yang masih digunakan untuk keperluan BKD dan kepangkatan, sehingga diharapkan tidak terjadi kehilangan dokumen penting dikarenakan penyimpanan yang tidak terstruktur.

Rancangan almari yang telah didesain dapat menjadi salah satu solusi untuk Dosen yang memiliki ruang kerja yang tidak terlalu luas. Pemilihan warna putih memiliki kesan luas pada ruangan dan pemilihan material yang ringan dan tidak terlalu mahal serta mudah untuk dibersihkan menjadi salah satu hal yang penting untuk dipertimbangkan dalam perancangan fasilitas kerja. Penerapan $5 \mathrm{~S}$ di ruang kerja Dosen memberikan penataan dokumen dan peralatan yang tertata rapi dan memiliki label penamaan dokumen, sehingga dokumen mudah teridentifikasi, menghemat waktu dalam pencarian, dan menerapkan budaya kerja $5 \mathrm{~S}$ di ruang kerja.

Hasil penilaian performansi 5S di ruang kerja Dosen menggunakan Office 5S Audit Checklist yang semula skor rata-rata sebesar 56,83 dengan kategori rating fair menjadi 92 dengan rating excellent. Hasil tersebut menunjukan peningkatan performansi $5 \mathrm{~S}$ mencapai hampir $50 \%$ sehingga dapat dikatakan bahwa metode $5 \mathrm{~S}$ dapat meningkatkan memperbaiki penyimpanan dokumen diruang kerja.

\section{Ucapan Terima Kasih}

Terima kasih kepada Fakultas Teknik Industri Universitas Trisakti yang telah membiayai penelitian ini. Terima kasih juga kepada para Dosen Teknik Industri Universitas Trisakti yang telah menyediakan waktunya untuk menjadi responden selama penelitian ini berlangsung.

\section{Daftar Pustaka}

Agustin.N, dan Purnomo.H. (2013). Implementasi 5S Pada CV. Valasindo Menggunakan Pendekatan Ergonomi Partisipatori. Jurnal Teknik Industri. [Diunduh : 6 September 2017]

A.D.Sari, F.I.Rahmillah, dan B.P.Aji. (2017). Implementation of 5S Method for Ergonomic Laboratory. IOP Conference Series : Materials Science and Engineering 215.

Gurel.D.A. (2013). A Conceptual Evaluation of 5S Model in Hotel. African Journal of Business Management. Vol7(30), PP 3035-3042. [Diunduh : 26 Januari 2018].

Gupta,S., dan Jain, S. (2015). An Application of 5S Concept to Organize the Work Place at a Scientific Instrument Manufacturing Company. International Journal of Lean Six Sigma, Vol 6 No. 1. India. [Diunduh : 7 November 2017].
Osada, T. (2016). Sikap Kerja 5S. Jakarta : Penerbit PPM.

Ramesh.K,MurugananthamV.R, \& Arunkumar.N.R. (2014). 5S Implementation Studies in Biomass Processing Unit. International Journal of Innovative Research in Science, Engineering and Technology. Vol.3 [Diunduh : 5 September 2017]

Soesilo.R. (2017). Implementasi Kaizen dan 5S Pada Pengeringan Produk Di Proses Plating. Jurnal Teknik Industri. Vo.18, No.02. [Diunduh : 7 November 2018].

Suwondo, Chandra. (2012). Penerapan Budaya Kerja Unggulan 5S di Indonesia. Jurnal Magister Manajemen. Vol. 1 No.1. [Diunduh : 7 November 2017].

Ulrich, K. dan Eppinger, S. (2001). Perancangan dan Pengembangan Produk. Jakarta : Salemba Teknika.

Widianti T, Damayanti S, dan Sumaedi S. (2015). Implementasi 5S Untuk Optimasi Keselamatan, Kesehatan, dan Performa Kerja. Prosiding Seminar Nasional Teknologi Pengelolaan Limbah XII. Tangerang Selatan. [Diunduh : 7 November 2017]. 